\title{
A Psicologia na formação de enfermeiros
}

\author{
Psychology in the education of nurses
}

\section{Carolina Silva Bandeira de Melo*}

Ecole de Hautes Edutes en Sciences Sociales - EHESS, Paris, França e Universidade Federal de Minas Gerais-UFMG, Belo Horizonte, Minas Gerais, Brasil

\section{Rodrigo Miranda**}

Universidade Federal de Minas Gerais-UFMG, Belo Horizonte, Minas Gerais, Brasil

\section{Sérgio Dias Cirino***}

Universidade Federal de Minas Gerais-UFMG, Belo Horizonte, Minas Gerais, Brasil

\section{Regina Helena de Freitas Campos****}

Universidade Federal de Minas Gerais- UFMG, Belo Horizonte, Minas Gerais, Brasil

\begin{abstract}
RESUMO
Analisamos o ensino de Psicologia na formação de enfermeiras, nas primeiras décadas do século XX, no Brasil. São apresentados aspectos relacionados a escolas de Enfermagem no Rio de Janeiro e em Belo Horizonte. Os tópicos desenvolvidos nos cursos de Psicologia no ensino de Enfermagem estavam ligados aos debates da Psicologia da época. Durante esse período, podemos observar mudanças na formação das enfermeiras de um modelo baseado na experiência para um novo modelo ancorado no conhecimento científico. O governo brasileiro apoiou essa mudança que estava vinculada a um contexto mais amplo do aumento da valorização das ciências no País. Os diferentes conhecimentos da Psicologia contribuíram para o estabelecimento de uma nova formação teórica e prática das enfermeiras. A análise do ensino de Psicologia na formação de enfermeiras contribui para uma melhor compreensão da Psicologia como disciplina no Brasil.
\end{abstract}

Palavras-chave: psicologia, enfermagem, ensino, historiografia.

\begin{abstract}
We analyze the teaching of psychology in the education of nurses in the first decades of the twentieth century in Brazil. We present aspects related to nursing schools from Rio de Janeiro and Belo Horizonte. Topics presented in the psychology courses in the education of nurses were connected to the psychological debates at that time. During this period, we can see the changing from a training based on working experiences to a new model based on the scientific knowledge. The Brazilian government sponsored this transformation, which was grounded in a broad context of the raising of the worth of sciences in the country. Psychological knowledge contributed for the establishment of a new theoretical and practical nursing training.
\end{abstract}


Analyzing teaching of psychology in the education of nurses contributes to a better understanding of psychology as a discipline in Brazil.

Keywords: psychology, nursing, teaching, historiography

\section{I ntrodução}

Nas primeiras décadas do século XX a presença da Psicologia, como disciplina científica, se disseminou em outras áreas do conhecimento, tais como a Medicina, a Educação e o Direito em diferentes partes do mundo. Essa presença também pode ser percebida no Brasil onde, além das relações estabelecidas com essas áreas do conhecimento, observam-se interfaces com a Enfermagem. No presente estudo, focalizamos a Enfermagem como um dos campos para a circulação dos conhecimentos da Psicologia no Brasil, através das disciplinas da área lecionadas em cursos de formação de enfermeiros no nível superior.

A análise do ensino de Psicologia na área da Enfermagem permite identificar elementos que remetem ao processo de disciplinarização da Psicologia. Segundo Gundlach (2006), uma disciplina é constituída por um conjunto de professores e estudantes, vinculados em torno de um corpo de conhecimentos teóricos e práticos minimamente canonizados. Particularmente, neste artigo, podemos observar quem eram os professores de Psicologia, algumas das instituições em que se encontravam, que disciplinas ministravam, como construíam uma identidade para a área da Psicologia através de seu ensino.

Nosso objetivo, assim, é descrever e analisar como se organizou o ensino de Psicologia em disciplinas lecionadas em três cursos de formação de enfermeiros no nível superior: a Escola de Enfermagem Alfredo Pinto; a Escola de Enfermagem Ana Nery (EEAN) e a Escola de Enfermagem Carlos Chagas (EECC). As duas primeiras estavam localizadas no Rio de Janeiro e foram criadas, respectivamente em 1921 e 1926. A terceira foi fundada em Belo Horizonte em 1933. Todas foram instituições de referência no desenvolvimento da Enfermagem no Brasil, e constituíram um campo propício à circulação de conhecimentos psicológicos nas primeiras décadas dos 1900 .

As três primeiras décadas do século XX (1900-1930) compuseram o período selecionado para a investigação. A seleção dessa temporalidade baseou-se em mudanças sociais e educacionais que permitiram e estimularam a participação da Psicologia em diferentes áreas do saber. Utilizamos como fontes históricos escolares de alunas ${ }^{1}$ dessas escolas, correspondências, quadros de professores e reportagens na imprensa escrita. Ao final, tendo abordado aspectos relacionados às disciplinas de Psicologia nessas escolas de Enfermagem, buscamos avaliar o campo da Enfermagem como espaço de circulação de conhecimentos da Psicologia nos 1900. 


\section{Modernização e urbanização: contextos para a Psicologia e a Enfermagem}

No Brasil, nas primeiras décadas do século XX, ocorreram diversas mudanças político-administrativas, além de modificações econômicas e sociais. Houve uma crescente urbanização, com aumento da população nas cidades, gerando um conjunto de demandas sociais. Podemos citar o exemplo de Belo Horizonte. Em 1912, a cidade possuía cerca de 40.000 habitantes; em 1935, a população girava em torno de 115.000 e, em 1950, 350.000 habitantes. Na capital federal, Rio de Janeiro, esse aumento também foi expressivo. Entre 1900 e 1920 , a população saiu de pouco mais de 800.000 habitantes para mais de 1 milhão. Dentre as demandas sociais, acentuadas pelo processo de desenvolvimento urbano-industrial, fortaleceram-se aquelas vinculadas à saúde e à educação públicas, que implicavam na necessidade de formação de profissionais para atendê-las (Fausto, 1994/2006).

$\mathrm{Na}$ área da educação, a partir dos anos de 1920, ocorreram diversas reformas, destinadas a expandir e modernizar os sistemas de ensino público, como por exemplo a Reforma Francisco Campos-Mário Casassanta realizada em Minas Gerais em 1927. No âmbito do ensino superior, nas primeiras décadas do século XX foram criadas escolas de formação de profissionais especializados, como a Faculdade de Medicina da Universidade de Minas Gerais (UMG) em 1911. Assim, uma das respostas para as demandas sociais foi a formação de profissionais que atuassem em instituições educacionais e de saúde pública. Oferecer assistência especializada aos doentes significou buscar, na ciência, soluções aos problemas da sociedade, o que, no passado, era função de entidades religiosas. Essa busca pelo conhecimento científico, de forte presença nos ideais republicanos, tornou-se imperiosa entre as elites intelectuais e políticas. Isso influenciou a criação das primeiras escolas de Enfermagem, no Brasil. As mudanças sociais, políticas e econômicas, ocorridas nas primeiras décadas do século $X X$, coincidem com o movimento de ordenação do espaço social proposto no seio da República. Durante esse período, uma das estratégias de ordenação do espaço social foi o investimento na saúde. Esse investimento estava atrelado ao cuidado do corpo, higiene e saneamento básico. De acordo com Nunes (2000), as elites político-econômicas e intelectuais promulgavam o mote ordenação e controle social, como formas de prevenção e correção das mazelas sociais e higiênicas dos agentes urbanos. Nas palavras da autora, o mote era: "observar, perguntar, apurar, descrever, contabilizar, agrupar, classificar. Em outras palavras: controlar e hierarquizar" (p.352). Associado a esse discurso, Monarcha (1992) aponta outro 
mote do período: "como a raça não se muda, que façamos dele [povo] saudáveis e educados" (p. 42). Nesse contexto de controle e prevenção social como medidas para minimizar consequências da industrialização e da urbanização, uma das explicações em voga era o higienismo (Silveira, 2008).

A urbanização e a industrialização geraram más condições sanitárias e elevada mortalidade, no país. De acordo com Gois Júnior (2000), podemos considerar o higienismo como um movimento, no Brasil, articulado por intelectuais com o intuito de produzir atenção à saúde e à educação dos habitantes da cidade. Esses intelectuais eram médicos, engenheiros e educadores, que em nome da ordem e do progresso, propunham medidas saneadoras de males físicos e sociais (Santos, 2006). Nesse sentido, esses intelectuais entendiam que a promulgação de cuidados com o corpo e com os aspectos mentais, produziria resultados no progresso social do país. Suas propostas de intervenções objetivavam a construção de um projeto profilático para o Brasil, no âmbito social, moral e comportamental. Esse grupo de intelectuais buscou contribuições de diversas áreas do conhecimento para subsidiar sua prática e encontraram, também na Psicologia, essas bases. Segundo Campos (2006, p.304): "Para os médicos, a Psicologia seria uma disciplina auxiliar para o propósito de diagnóstico das doenças mentais (tradução nossa)". Dessa maneira, os higienistas formaram um dos braços da Psicologia no Brasil, pois estimularam sua produção teórica.

A Psicologia, considerada como ciência afim à Psiquiatria, foi divulgada e desenvolvida no país por meio, por exemplo, das "Jornadas Brasileiras de Psicologia" (Antunes, 1998/2007). Nos dizeres da época: "A medicina, a pedagogia, a justiça, a organização do trabalho e outros ramos da vida prática e social reclamam, cada vez mais, o auxílio da Psicologia Experimental" (Guimarães, 1928, p. 387). Tudo isso fez parte do movimento de tornar o saber científico. Essa tendência estava presente desde o fim do século XIX e acentuou-se nos anos de 1920-30, na educação e na saúde. O enfoque na formação de especialistas, bem como as mudanças em prol da reorganização do espaço social foram especialmente evidentes na capital federal de então, o Rio de Janeiro. Como exemplo disso, observamos a criação da Escola de Enfermagem Alfredo Pinto (1921) e da Escola de Enfermagem Ana Nery (EEAN) (1926). Além da capital brasileira à época, outras cidades de diferentes estados estabeleceram políticas públicas de saneamento e ordenação social. O planejamento social alcançou o campo da saúde e, dentre as cidades que investiram nessas mudanças progressistas destaca-se Belo Horizonte. A capital mineira foi uma cidade planejada como forma de materializar a modernidade almejada pela República do Brasil. Na década de 1930, período em que Minas Gerais se 
destacou no cenário brasileiro, foi criada a Escola de Enfermagem Carlos Chagas (EECC) (1933) ${ }^{2}$.

\section{Psicologia e Enfermagem: ensinando Psicologia}

\section{Escola de Enfermagem Alfredo Pinto}

A Escola de Enfermagem Alfredo Pinto foi criada pela portaria de 1으 de setembro de 1921, expedida por Alfredo Pinto Vieira Melo, então Ministro da Justiça e Negócios Interiores. Ela já funcionava como seção feminina da Escola Profissional de Enfermeiros e Enfermeiras da Assistência a Alienados (criada pelo Decreto Federal n.791, de 27 de dezembro de 1890) e como recebia apoio do Ministro, recebia informalmente seu nome (Fundação Oswaldo Cruz, s/d) ${ }^{3}$. Em 22 de Setembro de 1942 a Escola de Enfermagem Alfredo Pinto fundiu-se à Escola Profissional de Enfermeiros e Enfermeiras da Assistência a Alienados, que passaram a funcionar em uma sede única, com o nome oficial de Escola de Enfermagem Alfredo Pinto, segundo o Decreto-lei no 4.725.

A Escola de Enfermagem Alfredo Pinto funcionava junto à Colônia de Psicopatas do Engenho de Dentro, que por sua vez, foi um importante lugar de desenvolvimento da Psicologia brasileira, sobretudo a partir da instalação, em 1923, do Laboratório de Psicologia Experimental, sob a responsabilidade de Waclaw Radecki (Centofanti \& Jacó-Vilela, 2007). Radecki (1887-1953) era polonês, foi chefe do Laboratório de Psicologia Experimental da Universidade de Cracóvia (Polônia) e assistente de Edouard Claparède, na Universidade de Genebra (Suíça). A convite de Gustavo Riedel, auxiliou na organização e na direção do Laboratório de Psicologia Experimental da Colônia de Psicopatas do Engenho de Dentro.

Esse laboratório foi instalado na seção feminina da Colônia (Guimarães, 1928). Assim, a seção de Psicologia estava fisicamente próxima à área da Enfermagem, uma vez que a Escola de Enfermagem Alfredo Pinto estava justamente na ala feminina. Além da produção de saberes psicológicos para o trabalho com a higiene e a profilaxia mental, o laboratório tinha por função o ensino de Psicologia. Em um relatório explicitando os instrumentos e as atividade desenvolvidas pelo laboratório de Psicologia, Guimarães (1928) afirma que o ensino de Psicologia era destinado a diferentes profissões da área de saúde, dentre elas, a Enfermagem. Especificamente sobre a formação de enfermeira, ele diz: "2 cursos de 25 horas cada um na Escola de Enfermeiras Alfredo Pinto" ( $p$. 393). Outras referências nos auxiliam a compor as disciplinas de Psicologia que eram ensinadas na Escola Alfredo Pinto (e.g. Antunes, 1998/2007; Porto \& Amorim, 2007). Esses trabalhos dizem que a 
disciplina Noções Gerais de Psicologia era ensinada no primeiro ano do curso. Com base no Dicionário Histórico-Biográfico das Ciências da Saúde no Brasil, da Fundação Oswaldo Cruz (s/d), havia uma terceira série, no curso de Enfermagem dessa Escola, com o objetivo de formar visitadoras sociais e, nesta terceira série, seriam ensinadas Noções Gerais de Psicologia.

Voltando ao relato de Guimarães (1928), observa-se que o ensino de Psicologia na Escola de Enfermagem Alfredo Pinto era de responsabilidade do laboratório de Psicologia. Ainda nesse relato, notamos que esse laboratório era um centro para a Psicologia Geral, Psicologia Individual, Psicologia Coletiva e Psicopatologia. No laboratório circulavam testes mentais (e.g. Binet-Simon), instrumentos vinculados à Psicologia Experimental (e.g. Ergógrafo de Mosso, Quimógrafo) e práticas psicoterápicas vinculadas à psicanálise. Esses instrumentos eram utilizados nas atividades do laboratório, tais como: no auxílio à prática médica de diagnóstico; exame de crianças nas escolas; investigações forenses; e o ensino de Psicologia (Guimarães, 1928). Assim, o ensino de Psicologia promovido por esse laboratório poderia cobrir uma série de campos. Essa fonte nos sugere, então, que a formação em Enfermagem ou das visitadoras sociais estava amparada por uma série de tópicos em Psicologia.

As visitadoras sociais foram um ramo de atuação da Enfermagem que, como sugere o nome, trabalhavam com a população, em suas casas, no intuito de prevenir, não apenas doenças infectocontagiosas, mas também doenças mentais. Apesar da divergência a respeito do ano do curso em que era oferecida, o dado importante é a existência da disciplina de Psicologia, no curso da Escola de Enfermagem Alfredo Pinto. A Psicologia parece pois ter desempenhado um papel relevante na formação para a atuação na saúde pública, no processo de modernização da República, auxiliando em ações preventivas para a saúde da população.

\section{Escola de Enfermagem Ana Nery}

A Escola de Enfermagem Ana Nery (EEAN) ${ }^{4}$ foi criada a partir da vinda de um grupo de enfermeiras dos Estados Unidos da América (EUA) ao Brasil, a convite do governo brasileiro. Dentre suas propostas para melhorar a saúde no país, estava a criação de um curso de treinamento de visitadoras domiciliares. Em fevereiro de 1923, a Escola de Enfermeiras Dona Anna Nery começou a funcionar com o nome de Escola de Enfermeiras do Departamento Nacional de Saúde Pública (DNSP). A partir do decreto n. 17.268, de 31 de março de 1926, passou a se chamar Escola de Enfermeiras Dona Anna Nery (Porto \& Amorim, 2007). 
Como no caso da Escola de Enfermagem Alfredo Pinto, a criação da EEAN estava relacionada à percepção da saúde como um problema econômico-social, no país. Isso também tinha relação com a Psicologia, pois "naturalmente, na profilaxia das moléstias mentais, está compreendida a profilaxia de outras moléstias capazes de favorecem ou ocasionarem perturbações físicas" (Guimarães, 1928, p.388). O próprio DNSP, ao qual a Escola Ana Neri estava vinculada, havia sido criado em 1920 como parte de uma ampla Reforma Sanitária liderada pelo médico sanitarista Carlos Chagas $^{5}$, conhecida como "Reforma Carlos Chagas", através da qual reorganizaram-se os serviços de saúde da capital da República. Almejava-se o controle das doenças transmissíveis, tais como a sífilis e a tuberculose. Esse contexto contribuiu, também, para o início da atividade de Enfermagem em saúde pública, por meio do trabalho da visitadora social (Paixão, 1969).

Pesquisadores da história da Enfermagem consideram que a criação dessa escola marca o início da Enfermagem "moderna", no Brasil. Uma das marcas do "moderno" encontrava-se na produção e no ensino de saberes científicos. Articulavam-se conhecimentos da Antropologia, Biologia, Pedagogia, Medicina e, também, Psicologia. A Psicologia surgia como uma ciência do indivíduo, que contribuiria para a compreensão científica da atividade mental e da conduta (Carvalho, 1997/2006; Monarcha, 1992). Nesse campo da ciência como dispositivo moderno, a Psicologia já estava imbuída da “(...) neutralidade científica e sob o signo do método experimental e da dedução de leis gerais ..." (Monarcha, 1992, p.47). Assim, na EEAN também veremos o ensino de Psicologia, contribuindo com a formação "moderna" em Enfermagem.

Paixão (1969) sugere que a EEAN é a primeira escola de Enfermagem de "alto padrão" do país. "Alto padrão" parece significar uma formação ancorada em saberes científicos. Machado (1995), nessa mesma direção, afirma que a EEAN foi "o mais importante fórum de decisões políticas e intelectuais da Enfermagem por cinco décadas" (p. 191). Para esse autor, isso significou que as enfermeiras formadas nessa Escola integraram o corpo docente da maioria das demais escolas de Enfermagem, além de terem sido importantes líderes na pesquisa e assistência de Enfermagem, no Brasil. Assim, observamos que as pesquisas em história da Enfermagem apontam a liderança da EEAN como instituição formadora no país.

A vinda da equipe de enfermeiras estadunidenses ao Brasil, em 1921, ocorreu em resposta ao pedido de Carlos Chagas ao International Health Board (Junta Internacional de Saúde), para organizar o serviço de saúde pública (Santos, 2006; Simões, Cristofolini, Oliveira, Carswell \& Azevedo, 1986). Essa missão foi subvencionada pela Fundação Rockfeller ${ }^{6}$, com a finalidade de promover a sustentação à Reforma Carlos Chagas. A equipe de enfermeiras recém-chegadas 
considerou a Enfermagem brasileira defasada em relação ao que se fazia em outros países, tais como os EUA. Os trabalhos realizados no Brasil consistiriam, em grande medida, na doação de objetos, de roupas pessoais, de roupas de cama e de alimentos, enquanto a enfermeira deveria ser reconhecida como uma reformadora social (Dornelles, 1995; Porto \& Amorim, 2007). A Fundação Rockfeller ofereceu apoio ao DNSP para organizar o serviço de enfermeiras e patrocinou o processo de desvinculação da atenção médica pelas associações religiosas (Dornelles, 1995). O incentivo para a criação de cursos de Enfermagem permitiu que, em alguns serviços de saúde, os profissionais com formação científica ocupassem o lugar dos leigos. As enfermeiras diplomadas, sob a supervisão das enfermeiras estadunidenses, com o apoio da Fundação Rockfeller e do governo, buscaram consolidar-se como tendo formação mais cientifica (Geovanini, 1995). No contrato da Fundação Rockefeller com o DNSP, em 1926, foi negociada uma regulamentação sobre a formação e a profissão de Enfermagem, o que foi garantido, em 1931, com o Decreto n. 20.109 (Moreira, 1995).

Nos históricos escolares de alunas do curso da EEAN, consta a disciplina Psicologia, ensinada no primeiro semestre de curso. $O$ ensino dos conteúdos de Psicologia e dessa disciplina, conforme consta nos históricos escolares, era realizado pelo médico sanitarista J. P. Fontenelle. Ele lecionava, também, as disciplinas de Higiene, Ciência Sanitária e Saúde Pública. Esse conjunto de disciplinas lecionadas pelo mesmo professor evidencia a presença de relações estreitas entre os saberes médicos e psicológicos no campo da higiene tanto física quanto mental nos espaços sociais. Outras fontes informam que os conteúdos de Psicologia eram abordados em uma disciplina com 6 a 8 horas de curso. Alunas da EEAN que se destacavam, ganhavam bolsas para complementar sua formação nos EUA. Dentre os documentos pesquisados na EEAN, encontramos uma carta da Escola de Enfermagem da Universidade de Cornell, de Nova Iorque, sobre o aproveitamento de uma aluna brasileira que por lá passou, além de alguns históricos acadêmicos, em inglês (History Card), onde a disciplina Psicologia estava presente.

A presença da Psicologia na EEAN foi um diferencial para a relação entre a Psicologia e a Enfermagem, pois, em 1931, a EEAN tornou-se escola modelo (Decreto n. 20.109 de 15 de junho). Assim, seu currículo e estrutura tornavam-se modelos para as demais escolas de Enfermagem que almejavam o "alto padrão" e uma formação "moderna". Os cursos de Enfermagem criados a partir dessa data - e mesmo os anteriores a 1931 - teriam que passar por um processo chamado equiparação, no qual, após uma inspeção, a escola seria, ou não, reconhecida. A Escola de Enfermagem Alfredo Pinto, por exemplo, conseguiu a equiparação em 1959. 
Ocorreu, na área de Enfermagem, um processo de legitimação na formação de enfermeiros. Esse movimento foi conflituoso, pois o campo de atuação do enfermeiro já existia no país e era ocupado por pessoas que não haviam necessariamente passado por uma formação profissional. As enfermeiras que se formavam na EEAN eram conhecidas com diplomadas, pois possuíam um diploma reconhecido pelo governo. A proximidade do governo brasileiro com a Enfermagem dos EUA beneficiou as diplomadas, nas disputas que se seguiram. A obrigatoriedade de um curso oficial que oferecesse, não apenas um ensino prático, mas contemplasse uma formação sobretudo teórica, foi conquistada pelas enfermeiras formadas na EEAN. Essa sistematização na formação diferenciou a profissão da Enfermagem da assistência social voluntária, oferecida por religiosos e pelas chamadas enfermeiras leigas. Dentre os conhecimentos científicos considerados necessários para essa formação teórica mais consistente na Enfermagem, encontra-se a Psicologia, servindo como arcabouço para diferenciar a assistência leiga do trabalho profissional.

\section{Escola de Enfermagem Carlos Chagas}

A terceira escola de Enfermagem, que compõe o universo investigado, é a Escola de Enfermagem Carlos Chagas (EECC), criada em 7 de julho de 1933, em Belo Horizonte, pelo decreto n. 10.952. A Escola é considerada a primeira do Estado e a pioneira na busca pela equiparação ao "Padrão Anna Nery" (Santos, 2006). A primeira diretora da EECC nos auxilia a compreender a presença da Psicologia desde os primeiros momentos da Escola. Sua primeira diretora da foi Laís Netto Reys ${ }^{7}$, do Rio de Janeiro. Ela esteve na Europa, em 1928, em viagem de estudos, onde concluiu vários cursos, inclusive o de Psicologia e pedagogia (Nascimento, Santos \& Caldeira, 1999). Os conhecimentos da Psicologia e da pedagogia agregavam valor à sua formação profissional.

Os documentos que encontramos sobre o ensino de Psicologia nessa Escola tinham datação dispersa entre os anos de 1933 e 1949. Assim, articulamos aquilo que foi encontrado com trabalhos anteriores sobre a EECC, a saber: Rosa (1999) e Santos (2006). Ao analisarmos os históricos escolares de alunas das primeiras turmas da EECC, verificamos a existência de uma disciplina de Psicologia, no primeiro ano de formação. Portanto, desde a sua criação, em 1933, o ensino de Psicologia fez parte do currículo do curso da EECC. De acordo com Santos (2006), essa disciplina era denominada Psicologia Aplicada à Enfermagem. Um dos documentos sobre a Escola contém informações sobre alguns de seus problemas e méritos, onde se destaca: “(...) o programa desse curso geral preenche as necessidades atuais da educação de uma enfermeira, tendo sido 
orientado pelo que há de mais moderno na profissão (grifos nossos)" (Costa \& Krisch, 1940, p.2). Mais uma vez podemos notar a colagem entre a ideia de uma escola de "alto padrão" com a formação "moderna". Nesse quadro a Psicologia aparecia como uma disciplina científica a contribuir na formação moderna que produziria uma profissional de alto padrão.

Estando incluída no programa do curso de Enfermagem, a Psicologia Aplicada à Enfermagem estava entre esses conhecimentos modernos, que preenchiam as necessidades da formação de uma enfermeira. A disciplina tinha uma carga horária de 20 horas. Em diversos documentos referentes à Escola, são citados oito professores da disciplina Psicologia na década de 1930 (ver Tabela 1).

\begin{tabular}{lc}
\hline \multicolumn{1}{c}{ Professor } & Ano/ Período \\
\hline Álvaro Negromonte (Padre) & 1936 e 1937 \\
Arlete A. Silva & 1948 \\
Armando Guerrazzi (Padre) & $1933-1944$ \\
Aspásia Vieira Ayer & 1947 \\
Aureliano Bastos & $1934-1938$ \\
J osé J oão Perna (Monsenhor) & 1935 \\
Sebastião de Souza Mesquita & $1946-1949$ \\
Waleska Paixão & $1935-1938$ \\
\hline
\end{tabular}

Tabela 1. Relação de Professores e Datas em que Lecionaram Psicologia na EECC.

Entre esses professores de Psicologia na EECC, tem-se representantes tanto religiosos quanto leigos. Esses dados são similares aos resultados de pesquisa encontrados nos estudos de história da Psicologia, demonstrando o papel de médicos e de religiosos no desenvolvimento da Psicologia, no Brasil (Antunes, 1998/2007; Massimi, 2005). Dentre os laicos, encontramos Arlete A. Silva, Aspásia Vieira Ayer, Aureliano Tavares Bastos e Waleska Paixão. O grupo dos religiosos era composto por Monsenhor José J oão Perna, Padre Armando Guerrazzi e Padre Álvaro Negromonte. Vemos, também, que o tempo de permanência deles como docentes da disciplina oscilou ao longo do anos. Esses professores também foram responsáveis por outros conteúdos. Waleska Paixão ministrou disciplinas de Línguas (Português e Francês); Aritmética; Cultura Religiosa; Nutrição; Cálculo e Soluções; Pesquisas Clínicas; Histologia; Higiene (Geral e Individual); Ética e História da Enfermagem. Padre Álvaro Negromonte foi responsável por Filosofia da Religião; Religião e Bases da Família. Aureliano Bastos, por sua vez, também ministrou Higiene Mental.

Waleska Paixão (1903 - 1993) foi convidada por Laís Netto Reys para lecionar no curso por sua experiência prática na área. Ela lecionou a disciplina Drogas e Soluções e a disciplina Psicologia, no curso de 
Enfermagem (Nascimento, Santos \& Caldeira, 1999). Todavia, ao ingressar na escola, ela não possuía a formação em Enfermagem. Ela foi simultaneamente aluna e professora da EECC. Ela assumiu a direção da EECC, em 1938, onde permaneceu até 1948, quando retornou ao Rio de Janeiro. Foi pioneira nos estudos de história da Enfermagem e, em 1983, recebeu o título de "Doctor Honoris Causa", pela Universidade Federal do Rio de Janeiro (UFRJ). O médico Aureliano Tavares Bastos, por sua vez, trabalhou no Instituto Raul Soares com o, também médico, lago Pimentel. Nesse Instituto, eles introduziram e incentivaram o uso das práticas psicológicas, sobretudo dos testes mentais, para auxiliar no diagnóstico psiquiátrico. Não conseguimos informações específicas sobre os demais professores laicos: Arlete A. Silva; Aspásia Vieira Ayer; e Sebastião de Souza Mesquita.

Acreditamos que Monsenhor Perna tenha sido teólogo. Não foram encontradas informações específicas sobre sua atuação na EECC. Porém, sua experiência como professor de Psicologia na Escola impactou sua trajetória. Em 1949 foi nomeado responsável pela cadeira de Psicologia da Faculdade de Filosofia, Ciências e Letras São Tomaz de Aquino, instalada na cidade de Uberaba (Minas Gerais). As proposições dessa Faculdade podem nos dar alguns indícios do ensino de Psicologia ministrado por ele: "Formar e aperfeiçoar a inteligência humana dentro das normas sadias dos princípios cristãos, eis a tarefa grandiosa a que se propõe a faculdade de Filosofia sob a inspiração da Igreja (grifos nossos)" (Correio Católico, 1949 apud Oliveira \& Gatti Jr., 2003). A escolha de Monsenhor Perna para essa faculdade, para além da vinculação religiosa, poderia ser influenciada por sua prática na EECC. Pelo menos, isso parece se aplicar para a disciplina sob sua responsabilidade: Psicologia.

Padre Armando Guerrazzi ingressou, em 1903, no Seminário Menor Metropolitano de Pirapora, onde cursou ciências humanas. Em São Paulo, ele iniciou seus estudos de Filosofia e Teologia e, em 1910, licenciou-se em Filosofia. Ele escreveu o livro O Linguajar da Criança (1942) e lecionou também na Escola de Aperfeiçoamento de Belo Horizonte. Padre Álvaro de Albuquerque Negromonte foi orientador religioso e hóspede permanente no internato das alunas da EECC. Ele escreveu, dentre outros: A Educação dos filhos (1955), O que fazer do seu filho (1955), Corrija seu filho (1961). São livros que apresentam relação estreita com temas da Psicologia da Educação. Álvaro Negromonte idealizava a aplicação dos ideais católicos com os "modernos conhecimentos da Psicologia Infantil" (Orlando \& Nascimento, 2007). Ele foi uma pessoa influente, teve contato com Helena Antipoff e esteve amplamente envolvido com a Psicologia, em Minas Gerais (Fazzi, 2005).

Assim como nas escolas do Rio de Janeiro, a EECC foi espaço para a circulação de conhecimentos psicológicos. Esses saberes circulavam 
pela atuação docente de diversos professores, com possíveis características particulares. Waleska Paixão era enfermeira, Aureliano Tavares médico, Álvaro Negromonte padre. A Psicologia circulava, então, a partir de diferentes referenciais que auxiliavam na formação das enfermeiras. Formação essa que vislumbrava, como nas demais escolas, um "alto padrão" de preparação a partir de disciplinas "modernas" e, portanto, científicas. No campo das disciplinas, podemos ver como os tópicos ministrados na disciplina de Psicologia pareciam estar conectados às produções em Psicologia. Não foram encontrados programas anteriores à década de 1940 (ver Tabela 2). Tomando como exemplo o programa de 1949, vemos vários conteúdos de Psicologia.

\section{Conteúdos}

Psicologia: definição, objeto, importância.

Alma vegetativa, sensitiva e intelectiva. Faculdade.

Sensação. Sentidos.

Percepção.

Estados Afetivos.

Emoções: causas, efeitos. Controle das emoções.

Algumas emoções: medo e cólera.

Simpatia, amor, amizade - Reações de defesa; sublimação.

Simpatia, amor, amizade - Compensação; sublimação (continuação).

Inteligência: tipos, medida. Etapas.

Aplicação de um Teste Mental (T).

Prova escrita sobre a matéria dada.

Comentário da prova. Memória.

Memória e testemunho.

I maginação.

Ligeira recapitulação - Atenção.

Aprendizagem - tipos. Leis.

Hábitos - características.

Hábitos - formação e eliminação.

Glândulas Endócrinas e Influências no Psiquismo

Fatores da Personalidade.

Tipos de Personalidade.

Prova Parcial.

Comentário da Prova Parcial.

Personalidade.

Personalidade Ajustada e Desajustada.

Vontade como Fator da Personalidade.

Aplicação das Noções às Doenças.

Psicologia da Enfermagem.

Prova Escrita Final.

Prova Oral.

Tabela 2. Programa da Disciplina Psicologia no curso da EECC, 1949. 
Primeiramente, vemos que a Psicologia cobria um grande conjunto de conteúdos pertinentes à área. Havia discussões sobre faculdades da alma, uma possível herança do século XIX (ver Assis \& Martins, 2012), bem como, assuntos relacionados à aprendizagem e extinção de hábitos. Os assuntos tratados parecem representar diferentes perspectivas dentro da Psicologia, tais como as psicodinâmicas (e.g. sublimação), as psicométricas (e.g. testes mentais), as experimentais (e.g. hábito - aprendizagem e extinção) e as biologicistas (e.g. glândulas endócrinas e influências no psiquismo).

Pelas disciplinas listadas, a Psicologia cobria assuntos relacionados a diversos aspectos, tais como emoções, inteligência, aspectos cognitivos, personalidade, e comportamento manifesto. A Psicologia apresentada nesse cronograma era, portanto, uma disciplina multifacetada. Essas diversas facetas sugerem contribuições da Psicologia em diferentes parcelas do fazer do enfermeiro. Por exemplo: memória e testemunho seriam temas relevantes no momento da anamnese de um paciente, de forma a contribuir na relação com esse paciente e no recolhimento de informações específicas para o tratamento. Podemos observar, também, discussões específicas sobre o controle das "pulsões" e de sentimentos negativos. Essa discussão estava provavelmente ancorada no pós-segunda guerra, em que havia várias propostas educativas para a democracia e a convivência pacífica em grupos (ver Antipoff, 1944/2002). Assim, essas temáticas nos auxiliam a compor aquilo que eram conteúdos considerados "modernos", "científicos", na formação das enfermeiras. Conteúdos que forneciam elementos para uma compreensão geral dos pacientes e possibilitavam intervenções ligadas não apenas ao corpo, mas aos aspectos mentais, emocionais e morais.

\section{Considerações finais}

Nosso objetivo neste artigo foi descrever e analisar aspectos relacionados ao ensino de Psicologia em três cursos de formação de enfermeiras no nível superior: a Escola de Enfermagem Alfredo Pinto; a Escola de Enfermagem Ana Nery e a Escola de Enfermagem Carlos Chagas. Isso nos permitiu observar que a Enfermagem foi um dos campos para a circulação da Psicologia no Brasil nas primeiras décadas do século XX, ao lado da Medicina, Pedagogia e Direito. Essa circulação esteve bastante vinculada às disciplinas de Psicologia e, portanto, na conformação de um grupo de professores e estudantes em torno de um corpo de conhecimentos teóricos e práticos minimamente canonizados. 
A relação entre Psicologia e Enfermagem, observada em nosso estudo, estava ancorada no contexto de profissionalização da Enfermagem. Contexto marcado: (a) pelo desenvolvimento de uma formação profissional sistematizada, a partir da criação de diferentes escolas de Enfermagem; e (b) pela acentuação de discursos de modernização e cientifização das práticas profissionais no Brasil. O argumento para o exercício da profissão com qualidade era a necessidade de uma formação não apenas prática, mas sobretudo teórica. Foi preciso, portanto, a construção de um arcabouço de disciplinas com o objetivo de incorporar e incrementar técnicas e teorias que subsidiassem a atuação profissional. Nesse quadro, a Psicologia integrou-se como disciplina auxiliar para formar um novo perfil de enfermeiras. Esse foi um dos importantes papéis da Psicologia no processo de organização e consolidação do campo da Enfermagem, no Brasil. A Psicologia contribuía na formação de "alto padrão" para as enfermeiras, pois compunha o quadro de disciplinas "modernas" e, portanto, científicas. Com a formação científica, as enfermeiras seriam "diplomadas" e poderiam criar novos dispositivos de inserção no espaço social. Espaço marcado pelo projeto profilático para o Brasil, com intervenções sociais, morais e comportamentais com o intuito de prevenir as doenças infectocontagiosas da população e as doenças mentais.

Identificamos que o ensino de Psicologia na Escola de Enfermagem Alfredo Pinto estava vinculado ao grupo de Psicologia da Colônia de Psicopatas do Engenho de Dentro, mais precisamente do Laboratório de Psicologia Experimental coordenado por Waclaw Radecki. Entretanto, não temos elementos precisos sobre os conteúdos ensinados, apesar de estarem relacionados com higiene, profilaxia mental, psicopatologia, Psicologia Experimental, dentre outros. O corpo docente da EEAN foi composto por estadunidenses e o conteúdo da disciplina de Psicologia estava vinculado também à higiene e à saúde pública. Nos dois espaços, identificamos o papel de estrangeiros no ensino e portanto na difusão da Psicologia no Brasil, tema que precisa ser mais estudado pela historiografia da Psicologia. Sobre a EECC, foi possível identificar os professores que lecionaram Psicologia, como os temas descritivos das aulas em 1949, o que nos sugeriu que os conteúdos da disciplina de Psicologia no curso de Enfermagem estavam conectados com as discussões da Psicologia nacional e internacionalmente.

Nosso estudo não permite generalizações para outras escolas de Enfermagem criadas no Brasil naquele período. Porém, ele contribui para a construção de uma historiografia das relações entre Psicologia e Enfermagem no país. Este estudo indica instituições relevantes, os professores que se dedicaram ao ensino de Psicologia para enfermeiras nas primeiras décadas do século $X X$ e os temas em Psicologia explorados nas disciplinas da área. É necessário um 
conjunto maior de pesquisas para que possamos mapear o ensino de Psicologia nos cursos de Enfermagem criados nas primeiras décadas dos 1900. Estudos que nos permitam observar, com mais detalhes: a formação e trajetória profissional dos professores; quais eram as disciplinas ofertadas e os conteúdos teóricos vinculados a essas disciplinas; e idealmente, quais as referências bibliográficas utilizadas e as perspectivas teóricas mais comuns. Além disso, há a necessidade de trabalhos que nos permitam descrever as relações entre Psicologia e higienismo nas escolas de Enfermagem. Dessa maneira, poderemos contribuir mais amplamente para uma melhor compreensão da história da Psicologia no Brasil.

\section{Referências}

Antipoff, H. (2002). Como pode a Escola Contribuir para a Formação de Atitudes Democráticas? In R. H. F. Campos (Org.) Helena Antipoff: textos escolhidos (pp. 221-226). São Paulo: Casa do Psicólogo. (Original de 1944).

Antunes, M. A. M. (2007). A Psicologia no Brasil: leitura histórica sobre sua constituição (5. Ed, Original de 1998). São Paulo: Marco Editora e EDUC.

Assis, R. M. \& Martins, J. S. (2012). Faculdades da Alma e suas Implicações para a Educação: saberes divulgados no século XIX. Educação e Pesquisa, 38, 97-114.

Bandeira de Melo, C. (2010). Ensino de Psicologia na Escola de Enfermagem Carlos Chagas (1933-1962). Dissertação de Mestrado em Educação, Universidade Federal de Minas Gerais. Belo Horizonte, MG, Brasil.

BRASIL, Congresso Nacional. Decreto n. 20.109 de 15 de junho de 1931. (1931). Regula o exercício da Enfermagem no Brasil e fixa, as condições para a equiparação das escolas de Enfermagem. Recuperado em 17 junho, 2009, de <http://www2.camara.gov.br/internet/legislacao/legin.html/visualiza rNorma.html?ideNorma $=544273 \&$ PalavrasDestaque $=>$

Campos, R. H. F. (2006). Scientific Psychology in Brazil in the 20th Century: The dialogue with European researchers, a look at Brazilian culture and a successful process of profissionalization. Physis: Rivista Internazionale di Storia della Scienza, XLIII, 301-317.

Carvalho, M. M. C. (2006). Quando a História da Educação é a História da Disciplina e da Higienização das Pessoas. In M. C. Freitas (Org.) História Social da Infância no Brasil (6. Ed, pp. 291-309). São Paulo: Cortez.

Centofanti, R. \& J acó-Vilela, A. M. (2007). O Laboratório de Psicologia na Colônia de Psicopatas em Engenho de Dentro. In R. H. F. Campos, 
F. \& Vieira, R. C. (Orgs.) Instituições e Psicologia no Brasil (pp. 150162). Rio de Janeiro: Nau.

Dornelles, S. (1995). Processo de trabalho e organização trabalhista. In T. Geovanini, A. Moreira, D. Schoeller \& W. C. A. Machado (Orgs.) História da Enfermagem - versões e interpretações (pp. 87-161). Rio de Janeiro: Revinter.

Fausto, B. (2007). História do Brasil (12. ed., 2a reimpressão). São Paulo: Universidade de São Paulo.

Fazzi, E. H. (2005). O laboratório de Psicologia da escola de aperfeiçoamento de Belo Horizonte: (1929-1946). Dissertação de Mestrado em Educação, Universidade Federal de Minas Gerais. Belo Horizonte, MG, Brasil.

Geovanini, T. (1995). Uma abordagem dialética da Enfermagem. In T. Geovanini, A. Moreira, D. Schoeller \& W. C. A. Machado (Orgs.) História da Enfermagem - versões e interpretações (1-39). Rio de Janeiro: Revinter.

Fundação Oswaldo Cruz (s/d). Dicionário Histórico-Biográfico das Ciências da Saúde no Brasil (1832-1930). Recuperado em 07 junho, 2009

de:

<http://www.dichistoriasaude.coc.fiocruz.br/iah/P/verbetes/escproen f.htm\#historico>

Gois Júnior, E. (2000). Os Higienistas e a Educação Física: a história dos seus ideais. Dissertação de Mestrado em Educação Física, Universidade Gama Filho. Rio de Janeiro, RJ, Brasil.

Guimarães, O. N. S. (1928). O Laboratório de Psicologia. In Colônia de Psicopatas de Engenho de Dentro: Laboratório de Psicologia da Colônia de Psicopatas de Engenho de Dentro (pp. 387-415). Rio de Janeiro: Colônia de Psicopatas de Engenho de Dentro.

Gundlach, H. (2006). Psychology as science and as discipline: the case of Germany. Physis: Rivista Internazionale di Storia della Scienza, XLIII, 61-89.

Machado, W. C. A. (1995). Reflexão sobre a prática profissional do enfermeiro. In T. Geovanini, A. Moreira, D. Schoeller \& W. C. A. Machado (Orgs.) História da Enfermagem - versões e interpretações (pp. 164-204). Rio de Janeiro: Revinter.

Massimi, M. (2005). O processo de institucionalização do saber psicológico no Brasil do século XIX. In A. M. Jacó-Vilela, A. A. L. Ferreira, F. T. Portugal (Orgs.) História da Psicologia - rumos e percursos (pp. 159-168). Rio de Janeiro: Editora NAU.

Minas Gerais. Secretaria do Interior. Decreto n. 6.831, de 20 de março de 1925 (1925). Aprova o regulamento do ensino nas Escolas Normais no Estado. Coleção das Leis e Decretos do Estado de Minas Gerais. Belo Horizonte: Imprensa Oficial.

Monarcha, C. (1992). As Três Fontes da Pedagogia Científica: a Psicologia, a sociologia e a biologia. Didática, 28, 41-49. 
Moreira, A. (1995). Desmistificando a origem da Enfermagem brasileira. In T. Geovanini, A. Moreira, D. Schoeller \& W. C. A. Machado (Orgs.) História da Enfermagem - versões e interpretações (pp. 41-86). Rio de Janeiro: Revinter.

Nascimento, E. S; Santos, G. F. \& Caldeira, V. P. (1999). Criação, quotidiano e trajetória da Escola de Enfermagem da UFMG (pp. 2641). Belo Horizonte: Escola de Enfermagem da UFMG.

Nunes, C. (2000). Anísio Teixeira: a poesia da ação. Bragança Paulista: EDUSF.

Oliveira, S. J. \& Gatti J r, D. (2003). A Formação do Professor em Dois Tempos. In: Anais do II Congresso de Pesquisa e Ensino em História da Educação em Minas Gerais (pp. 244-252). Uberlândia: Editora da Universidade Federal de Uberlândia.

Orlando, E. A. \& Nascimento, J. C. (2003). A I greja Católica e a Educação Brasileira: Álvaro Negromonte e o Discurso de Moralização da Nação. Scientia plena, 3(5), 180-185. Recuperado em 08 janeiro, 2010 de: <http://www.scientiaplena.org.br/sp_v3n5p180_185.pdf> Paixão, W. (1969). História da Enfermagem (4. ed. rev. e aumentada). Rio de Janeiro: Bruno Buccini.

Porto, F. \& Amorim, W. (Orgs.). (2007). História da Enfermagem brasileira: lutas, ritos e emblemas. Rio de Janeiro: Águia Dourada.

Santos, G. F. (2006). Escola de Enfermagem Carlos Chagas (19331950): a Deus - pela humanidade - para o Brasil. Tese de Doutorado em Educação, Universidade Federal de Minas Gerais. Belo Horizonte, MG, Brasil.

Silveira, R. D. (2008). Projeto Lopes Rodrigues: continuidades e rupturas nas conexões entre ensino psiquiátrico e prática assistencial em Minas Gerais (1920-1930). Tese de Doutorado em Educação, Universidade Federal de Minas Gerais. Belo Horizonte, MG, Brasil.

Simões, C., Cristofolini, L., Oliveira, M. H. P., Carswell, W. A. \& Azevedo, D. (Orgs.). (1986). Considerações sobre: modalidades da assistência de Enfermagem no Brasil no período de 1900 a 1945. Bauru: Universidade de Sagrado Coração.

\section{Endereço para correspondência}

Carolina S. Bandeira de Melo

Centre Alexandre Koyré 27, Rue Damesme, Code postale 75013, Paris, France

Endereço eletrônico: carolina.bmelo@yahoo.com.br

\section{Rodrigo Lopes Miranda}

Faculdade de Educação. UFMG.

Av. Antônio Carlos, 6627, Pampulha, CEP 31270-901, Belo Horizonte - MG, Brasil

Endereço eletrônico: dingoh@gmail.com

\section{Sérgio Dias Cirino}

Faculdade de Educação. UFMG.

Av. Antônio Carlos, 6627, Pampulha, CEP 31270-901, Belo Horizonte - MG, Brasil

Endereço eletrônico: sergiocirino99@yahoo.com

Regina Helena de Freitas Campos

Faculdade de Educação. UFMG. 
Av. Antônio Carlos, 6627, Pampulha, CEP 31270-901, Belo Horizonte - MG, Brasil Endereço eletrônico: regihfc@terra.com.br

Recebido em: 30/03/2012

Reformulado em: 04/07/2013

Aceito para publicação em: 21/09/2013

Acompanhamento do processo editorial: Ana Maria Jacó-Vilela

\section{Notas}

* Doutoranda na Ecole de Hautes Edutes en Sciences Sociales, Paris, França em cotutela com a Faculdade de Educação da Universidade Federal de Minas Gerais. Bolsista de doutorado Capes.

** Doutorando da Faculdade de Educação da Universidade Federal de Minas Gerais. Bolsista de doutorado CAPES.

*** Professor de Psicologia na Universidade Federal de Minas Gerais, Belo Horizonte/MG, Brasil. Doutor em Psicologia pela USP.

**** Professora titular de Psicologia da Educação na Universidade Federal de Minas Gerais, Belo Horizonte/MG, Brasil. PhD em Educação pela Stanford University, EUA.

1 Utilizamos o termo no feminino, pois, historicamente foram as mulheres que definiram os contornos da profissão da Enfermagem e nos primeiros cursos oferecidos a turma foi eminentemente feminina. Para maiores informações, sugerimos a leitura de Bandeira de Melo, 2010.

2 A Escola de Enfermagem Carlos Chagas foi criada desvinculada da Universidade de Minas Gerais (UMG), apenas na década de 1950 ela foi incorporada a essa universidade.

${ }^{3}$ No material estudado, encontram-se grafias diferentes para o nome da Escola e optou-se por essa escrita. Ana Justina Ferreira Néri (1814 - 1880), homenageada com o nome da Escola, voluntariou-se para cuidar dos feridos da Guerra do Paraguai (1864-1870), recebendo do governo brasileiro condecoração por sua atuação.

${ }^{4}$ Carlos Chagas (1879-1934) ingressou, em 1907, no Instituto Oswaldo Cruz (IOC). Em 1917, após a morte de Oswaldo Cruz, assumiu a direção do IOC, onde trabalhou durante toda sua vida. Conhecido por ter descoberto a doença de Chagas, foi nomeado diretor do DNSP, em 1920, quando da criação do mesmo pela Lei 3.987 (de 2 de Janeiro de 1920, que Reorganiza os serviços da Saude Publica), em substituição à antiga Diretoria Geral de Saúde Pública.

${ }^{5}$ A Fundação Rockefeller foi criada em 1913, por iniciativa do milionário John D. Rockefeller, com o objetivo de implantar, em vários países, medidas sanitárias baseadas no modelo dos Estados Unidos. Para mais informações: <http://www.coc.fiocruz.br/areas/dad/guia_acervo/arq_pessoal/fundacao_rockfelle r> ou ainda: <http://www.rockfound.org/ab̄out_us/history/timeline.shtml>

${ }^{6}$ Laís Moura Netto dos Reys (1893 - 1950) formou-se na primeira turma da Escola de Enfermagem Anna Nery; fundou a EECC, onde foi diretora até 1938, quando retornou ao Rio e assumiu a direção da Escola de Enfermagem Anna Nery.

${ }^{7}$ Documento primário, de três páginas, em papel timbrado: Ministério da Educação e Saúde, Universidade do Brasil, Escola de Enfermeiras Anna Nery, Rio de Janeiro, 29 de Outubro de 1940, assinado por Aurora de Afonso Costa e Hilda Anna Krisch. 